\title{
Our Experience in the Treatment of Vertebrobasilar Insufficiency Due to Cervical Spine Disorders
}

\author{
Beslan S. Dzhilkashiev ${ }^{1,2 *}$, Gennadiy I. Antonov ${ }^{1,2}$, Gennadiy E. Chmutin ${ }^{1}$, Keith Simfukwe ${ }^{1}$, \\ Edward R. Miklashevich², \\ ${ }^{1}$ Peoples' Friendship University of Russia (RUDN University), \\ 6 Miklouho-Maclay Str., 117198 \\ Russian Federation \\ 23-d Central Military Clinical Hospital named after A.A. Vishnevsky of the Ministry of Defense of the \\ Russian Federation, \\ 1 Novyy Village, 143420 \\ Russian Federation
}

Received: January 4, 2021. Revised: July 9, 2021. Accepted: July 23, 2021. Published: July 30, 2021.

\begin{abstract}
This article defines vertebra-related causes of vertebrobasilar insufficiency in patients with the signs of tortuosity of segment VI of the VA. The aim of this study is to present the results of diagnostics of discirculatory phenomena in the vertebrobasilar system and to show their importance for differentiated surgical treatment of stenotic lesions of segment V1 of VA in pathological disorders of cerebral circulation in the VBS caused by osteochondrosis of the cervical spine. The following traditional methods are used in diagnostics: Doppler ultrasonography, multispiral computed tomography with contrast enhancement. Also using developed by the author method for determining VA reactivity and circulatory insufficiency in the vertebrobasilar system (VBS). Based on our methodology and criteria, patients were selected for different types of surgical treatment with clinical outcome prediction following interventions on the arteries of the VBS. To determine the pathologies of the intracranial segments of the vertebral and basilar arteries, taking into account the pathways of collateral compensation in the VBS, cerebral angiography is recommended before surgery on the arteries of the VBS. Reconstructive techniques used on segment VI of the VA will predictably show the best longterm clinical results. The excision of a tortuous segment VI of the VA may be effective in obtaining reliable results of successful interventions in the early postoperative period. The conservative treatment of the patients with multiple
\end{abstract}

VBD lesions is possible. early outcomes of their use are satisfactory.

Keywords - cervical osteochondrosis; vertebral artery; blood circulation; surgical treatment.

\section{INTRODUCTION}

Circulatory disorders of the vertebral and basilar arteries are common manifestations of cervical osteochondrosis at the initial stages of the disease (about $88 \%$ ) [1]. The disease results in disability and, if not treated, in the development of chronic discirculatory encephalopathy, cervical myelopathy, or ischemic stroke, and significant disability of the patients. In foreign practice, the relationship between a degree of cerebral neurological insufficiency and vascular lesions at various clinical and morphological stages of cervical osteochondrosis has been confirmed [2]. At the initial stages of the disease, vertebrobasilar circulatory disorders are a consequence of sympathetic (reflex) or compressive-irritative (compressionreflex) processes in the vertebral arteries. At the first stage, the initial dystrophy of the intervertebral disc is manifested as a decrease in the amortization capacity of the nucleus pulposus, which results in a mild disorder of the anatomical integrity of the annulus fibrosus, irritation of its peripheric receptors, and, as a consequence, irritation of the perivascular sympathetic plexus of the vertebral arteries - a discirculation develops. The second stage of the disease is a consequence of the progression of histochemical and pathomorphological processes of the first stage. The loss of fixation properties by 
the annulus fibrosus results in the instability of the spinal motor segment [3], resulting in dynamic narrowing of the spinal canal, irritation, and compression of the vertebral arteries.

Treatment of the neurological syndrome of cervical osteochondrosis is quite complicated. The most problematic is the treatment at the second stage of the disease. The development of a technique to stabilize the spinal motor segment due to optimized blood circulation is urgent. Various manipulations are known from the scientific literature, however, a comprehensive treatment of osteochondrosis of the spine is normally described, aimed at the elimination of the process both in the spinal motor segment and in the foci of pathological impulses from the periphery. However, without taking into account the function of the circulatory system, even a comprehensive pathogenetic therapy does not provide timely remission and proper sanogenesis [4].

It is important to take into account that many types of reconstructive interventions in VA stenosis are characterized by persistent disability, deep disadaptation, which significantly worsens the quality of life of patients of predominantly working age, making them inferior in the social and labor sphere and burdensome in everyday life. The resistance of the symptoms of this type of disease to conventional medications makes the treatment ineffective in most cases. The use of vascular-active, anticoagulant and antiplatelet agents and neuroprotectors in the comprehensive therapy of cerebral circulatory insufficiency has largely exhausted its potential and does not result in a significant improvement in treatment outcomes.

Unstable results of surgical treatment of VA stenosis are due to the lack of an optimal diagnostic algorithm to determine the nature, degree, and level of cervical spine disorders as the basis for the type of surgical intervention selection in critical vasoconstriction [5-15]. The system of indications for surgical treatment in tortuosity of segment VI of the VA and the issues of differentiated use of various techniques of reconstructive surgery and prediction of their results are insufficiently developed.

The aim of this study is to present the results of diagnostics of discirculatory phenomena in the vertebrobasilar system and to show their importance for differentiated surgical treatment of stenotic lesions of segment V1 of VA in pathological disorders of cerebral circulation in the VBS caused by osteochondrosis of the cervical spine.

\section{MATERIALS AND METHODS}

During this study, treatment outcomes in 50 patients with the signs of VBI caused by osteochondrosis of the cervical spine in the acute phase, were studied. The patients were young and middle-aged (25-59 years old). All patients were admitted to the Federal State Budgetary Institution A.A. Vishnevsky 3rd CMCH of the Russian Ministry of Defense from 2009 to 2019, inclusive, or transported by an ambulance. They had been ill for more than a year; treatment in neurological hospitals was ineffective.

According to our observations, the pathology accounted for $27 \%$ of all cases of transient cerebral circulatory disorders. In all $27 \%$ of the examined patients ( 20 patients), vertebrobasilar insufficiency was proved and various significant stenoticocclusive lesions of the V1 segment of the arteries were observed. The clinical diagnosis at the initial stage was determined and recorded in the patient individual record forms, specifying pathological tortuosity of the vertebral arteries.

Vascular disorders were major manifestations of the instability of the spinal motor segment. They were of a longterm but inconsistent nature and were associated with movements in the neck, often intensified during sleep or at the end of a working day, aggravated in spring and autumn. Short, incomplete remissions were typical. This course of osteochondrosis of the cervical spine was due to the severity of the compressive-irritative processes with constant sympathicotonia.

Dyscirculatory phenomena had the following clinical symptoms:

- permanent autonomic disorders (in $48 \%$ of patients);

- impaired vascular innervation (increased blood pressure in $27 \%$ of patients, decreased blood pressure in $41 \%$ of patients);

- minor cerebral disorders (in 11\% of patients);

- hypersomal syndrome (in $2 \%$ of patients).

- Intermittent changes in vertebrobasilar circulation caused by compressive-irritative processes were manifested as:

- syncopal vertebral paroxysms ("drop attacks" in 34\% of patients, Unterharnscheidt's syncopal vertebral syndrome in $2 \%$ of patients);

- autonomic crisis (in $45 \%$ of patients);

- severe cerebellar disorders (in 3\% of patients);

- bulbar palsy (NCVE - in 8\% of patients, ACVE - in 3\% of patients).

Circulation through the vertebral arteries was significantly impaired in almost $60 \%$ of patients, through the basilar artery - in almost $20 \%$ of patients. Functional tests showed that the circulation through the vertebral arteries can decrease to the level of critical stenosis or more, or it can disappear in one of the arteries: there is a circulatory insufficiency through the basilar artery (up to 70\%) with the steal syndrome.

All 50 patients were assigned to the Surgical Treatment group depending on the prevailing dysfunction of VBS blood supply with stenotic-occlusive involvement of the segment V1 of the VA. Indications for hospitalization in all 100 patients included: significant clinical symptoms in the VBS; for the Surgical Treatment group, lack of clinical effects of pharmacotherapy carried out under the supervision of a neurologist for at least 6 months. After patients were admitted to the hospital, a clinical examination was carried out to address the problem of surgical treatment and determine the nature of the intervention. 


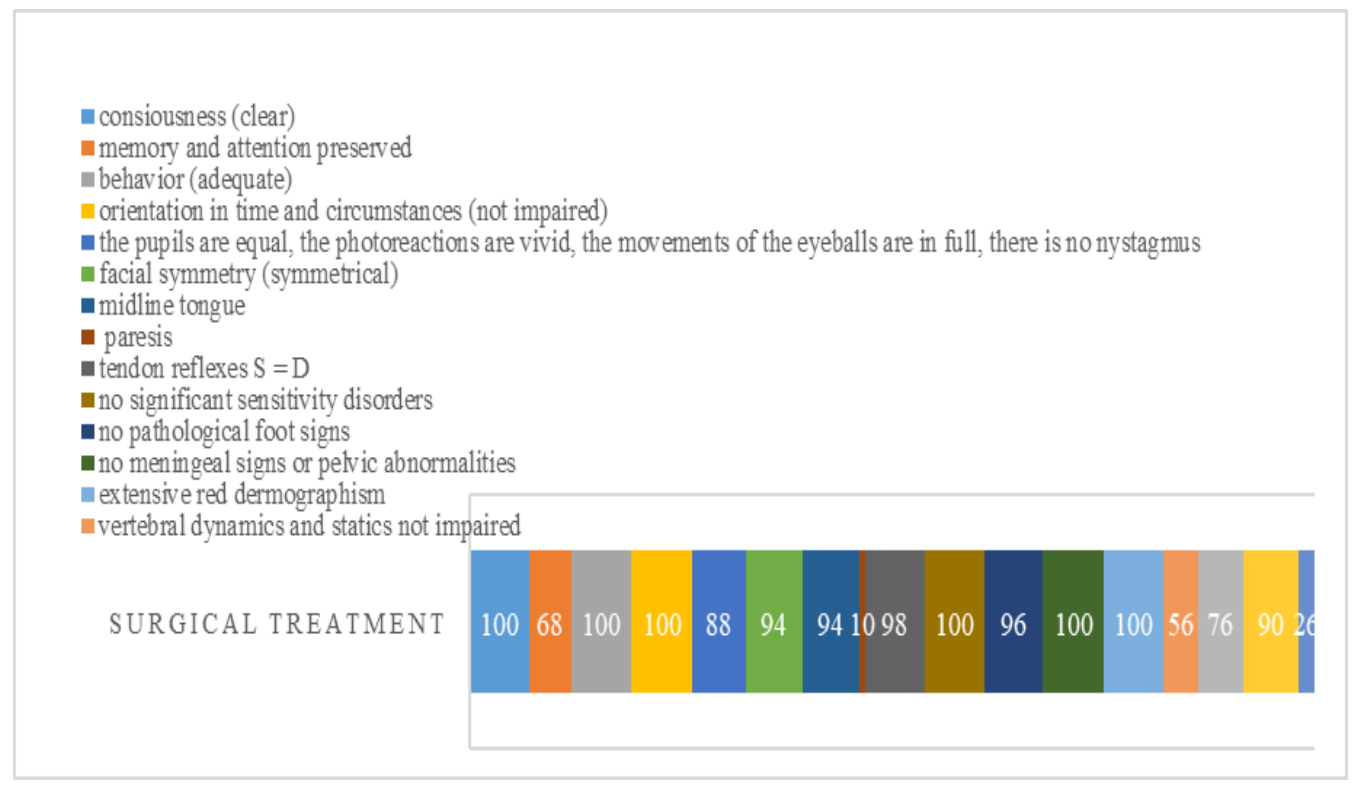

FiguRE 1. NEUROLOGICAL STATUS OF PATIENT

The evidence base for the VBI syndrome included a mandatory combination of discoordination, vestibular ataxia, auditory and visual disorders $[1 ; 16 ; 17]$. Objectively proven neurological symptoms showed focal lesions in the brainstem structures.

As shown in Figure 1, vertebrobasilar circulatory disorders are always associated with local pain syndromes and movements in the cervical spine. Despite the recognized efficiency of surgical interventions in VA stenosis, they are still used only for individual, situational indications in segment VI of the VA [18-23]. The theoretical grounds for surgical treatment of stenosis of the vertebrobasilar arteries in this segment have not been sufficiently developed, and the absence of standard techniques for their implementation results in unstable outcomes.

\section{RESULTS}

The study used the elements of various reconstructive interventions; besides, hybrid interventions were performed on the vertebrobasilar arteries. The assessment of the total severity of various VBI manifestations and their changes before and after surgery was performed using the Hofferberth scale. The number of reconstructive interventions performed in the Surgical Treatment group is presented in Table 1.

\section{TABLE 1. A NUMBER OF INTERVENTIONS PERFORMED}

\begin{tabular}{|c|c|c|c|c|}
\hline & Intervention & $\begin{array}{l}\text { Number of } \\
\text { interventions }\end{array}$ & Subgroups & \\
\hline \multicolumn{5}{|c|}{ Surgical Treatment group $(n=50)$} \\
\hline I. & anastomosis & 6 & Left vertebral and common carotid artery anastomosis. & 6 \\
\hline \multirow[t]{5}{*}{ II. } & tortuosity excision & 35 & $\begin{array}{l}\text { Tortuosity excision with redressing and reimplantation of the ostium of the right } \\
\text { vertebral artery. }\end{array}$ & 3 \\
\hline & & & $\begin{array}{l}\text { Excision of the left vertebral artery from the ostium, left vertebral and common } \\
\text { carotid artery anastomosis. }\end{array}$ & 2 \\
\hline & & & $\begin{array}{l}\text { Tortuosity excision with redressing and reconstruction of the left vertebral } \\
\text { artery ostium. }\end{array}$ & 24 \\
\hline & & & Pathologic tortuosity excision of segment $1 \mathrm{~V}$ of the left vertebral artery. & 5 \\
\hline & & & $\begin{array}{l}\text { Excision of the right vertebral artery, reconstruction of the ostium, } \\
\text { reimplantation in the right SCA. }\end{array}$ & 1 \\
\hline III. & arteriolysis & 3 & Arteriolysis, desympathization, arteriopexy of the left VA and SCA. & 1 \\
\hline
\end{tabular}




$\begin{array}{lll}\begin{array}{l}\text { IV. endovascular } \\ \text { stenting of the } \\ \text { ostium }\end{array} & 1 & \begin{array}{l}\text { Endovascular stenting of the ostium of the left vertebral artery under } \\ \text { radiological control. The lumen of the artery was restored. }\end{array} \\ \text { V. Repair } & 1 & \begin{array}{l}\text { Repair of the ostium of the right vertebral artery. } \\ \text { Additional techniques }\end{array} \\ & 1 & \begin{array}{l}\text { Angioplasty, stenting of the right vertebral artery. } \\ \text { Left scalotomy. } \\ \text { Left eversion carotid endarterectomy. Excision of the pathological loop and }\end{array}\end{array}$
redressing of the left vertebral artery.

At the same time, angioplasty, stenting of the right vertebral artery; left scalotomy; left eversion carotid endarterectomy, excision of the pathological loop, and redressing of the left vertebral artery were additionally performed in the group.

At the first stage of surgery, the purpose of our study was to achieve the best treatment outcome in discirculatory signs of spinal motor segment instability. Patient preoperative preparation was carried out taking into account the nature of the observed concomitant pathology, as well as the volume of the forthcoming surgical intervention. Regardless of the type of concomitant pathology, antiplatelet and sedative drugs were prescribed to all patients in the preoperative period. In severe dizziness, patients have prescribed betahistine hydrochloride at a dose of 16 to $32 \mathrm{mg}$ daily. Concomitant pathologies were managed by cardiologists, pulmonologists, and endocrinologists.

In the postoperative period, the patients were examined on the 10th day, after 1 and 3 years and later. Examinations included general clinical and neurological examinations with the identification of the patients with VBI clinical symptoms and their changes. Preservation, reduction or disappearance, of subjective symptoms and objective neurological data were determined. Also, instrumental methods were used to determine the state of the anastomosis area and the functional characteristics of circulation through the brachiocephalic vessels.

To select patients with VBI clinical symptoms for surgical treatment, 50 patients were examined according to the same developed algorithm. First, other diseases that could mask VBI were excluded. Then an actual diagnosis was established - the nature and place of the damage to the artery was established. Then topical diagnostics was carried out - the nature and location of arterial damage associated with osteochondrosis was established. CT angiography to assess the outflow pathways through the intracranial arteries segment IV of the VA and the basilar artery, as well as the state of the retromastoid anastomosis - was considered an obligatory element of the examination.

\section{DISCUSSION}

This study allowed for determination of the presence/absence of posterior type tortuosity of venous blood flow (absence of PCA) in all patients with VBI, type of collateral compensation, and indications for a specific type of surgical treatment. A statistical analysis of circulation parameters before and after surgery was performed in all patients with clinical manifestations of VBI and involvement of segment VI of the VA after surgery. At the same time, significant differences were established regarding the persistence or disappearance of VBI clinical symptoms for the reactivity index $(\mathrm{RI})(\mathrm{p}<0.05)$. In the group of patients after surgery, favorable results, including a decrease or disappearance of VBI clinical symptoms, were observed in the patients who had an increased reactivity index up to 0.3 or higher (CI more than 30\%).

Unfavorable results - deterioration or recurrence of VBI clinical symptoms in the patients with reactivity index less than 0.3 after surgery (CI less than $30 \%$ ). The data is presented in Figure 2. 


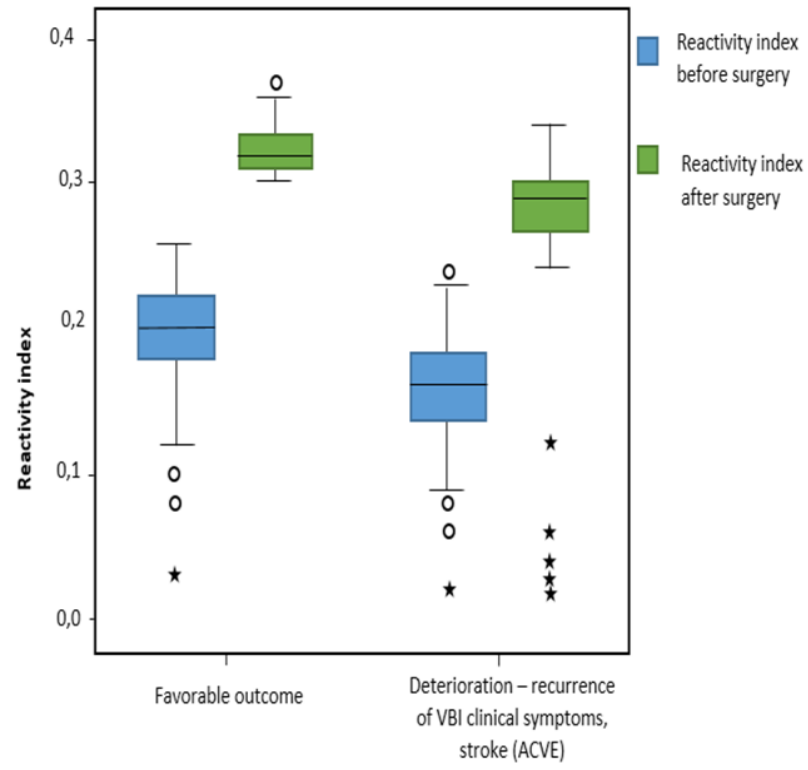

FIGURE 2. INDEX OF VA REACTIVITY DEPENDING ON VBI CLINICAL SYMPTOMS BEFORE AND AFTER SURGERY.
Doppler mapping of the VA. From the access at the angle of the mandible, linear and volumetric blood flow rate along the VA in segment VI was recorded, mean blood flow rate was determined and a test was performed with the patient holding his breath for 30 seconds. The VA reactivity index was calculated using the formula:

$$
\mathrm{RI}=\mathrm{Y} 2-\mathrm{VI} / \mathrm{Y} 2 * 100 \% \text {, }
$$

where RI - reactivity index; VI - mean blood flow rate before the test; Y2- mean blood flow rate after the test.

Then, the VA was studied from the opposite side with determination of the reactivity index and the volumetric blood flow rates for both VAs was summed up.

Results with similar reactivity index values were obtained in the patients when they were divided into groups according to the initial form of VBI (Table 2). To control the results obtained, the data of the Conservative Treatment group were used - a sample of 50 patients who received pharmacotherapy during the observation period and were not operated on.

To determine VA reactivity and circulatory insufficiency, we used our method. The essence of the proposed method is that the subject, in the supine position, underwent color

TABLE 2. CHARACTERISTICS OF BLOOD FLOW IN SEGMENT IV OF THE VA, DEPENDING ON THE TYPE OF VBI

\begin{tabular}{|c|c|c|c|c|}
\hline & $\begin{array}{l}\text { DEP } \\
\text { VBI } 1\end{array}$ & $\begin{array}{c}\text { TIA } \\
\text { VBS } 2\end{array}$ & $\begin{array}{l}\text { ACVE } \\
\text { VBS } 3\end{array}$ & $\begin{array}{c}\text { Control group } \\
\text { (Conservative } \\
\text { treatment) }\end{array}$ \\
\hline & $\mathbf{M} \pm \mathbf{S D}$ & $\mathbf{M} \pm \mathbf{S D}$ & $\mathbf{M} \pm \mathbf{S D}$ & $\mathbf{M} \pm \mathbf{S D}$ \\
\hline Age at the time of surgery & $59.06 \pm 8.28$ & $69.12 \pm 7.70$ & $70.27 \pm 7.60$ & $76.12 \pm 7.70$ \\
\hline $\begin{array}{l}\text { Time from the onset of the disease to } \\
\text { surgery }\end{array}$ & $4.61 \pm 2.97$ & $4.80 \pm 2.84$ & $3.97 \pm 2.27$ & - \\
\hline Blood flow before $\mathrm{VA}, \mathrm{ml} / \mathrm{min}$ & $62.13 \pm 20.60$ & $62.70 \pm 22.18$ & $63.13 \pm 17.09$ & $62.98 \pm 29.11$ \\
\hline Blood flow after $\mathrm{VA}, \mathrm{ml} / \mathrm{min}$ & $117.79 \pm 23.99$ & $116.57 \pm 17.54$ & $115.92 \pm 17.48$ & $120.88 \pm 23.54$ \\
\hline $\begin{array}{l}\text { Increase in blood flow through VA, } \\
\mathrm{ml} / \mathrm{min}\end{array}$ & $54.56 \pm 22.63$ & $55.96 \pm 19.73$ & $52.80 \pm 17.73$ & $55.96 \pm 19.73$ \\
\hline $\begin{array}{l}\text { Total blood flow in both VAs before } \\
\text { surgery/treatment, } \mathrm{ml} / \mathrm{min}\end{array}$ & $207.81 \pm 22.33$ & $210.16 \pm 29.81$ & $216.16 \pm 23.37$ & $220.11 \pm 28.82$ \\
\hline $\begin{array}{l}\text { Total blood flow in both VAs after, } \\
\mathrm{ml} / \mathrm{min}\end{array}$ & $262.76 \pm 36.29$ & $264.08 \pm 42.62$ & $271.36 \pm 23.99$ & $224.18 \pm 14.32$ \\
\hline Increase in total blood flow in both VAs & $54.96 \pm 30.80$ & $53.92 \pm 36.21$ & $55.20 \pm 24.96$ & $53.652 \pm 25.65$ \\
\hline Reactivity index before surgery/treatment & $0.181 \pm 0.043$ & $0.171 \pm 0.070$ & $0.197 \pm 0.038$ & $0.198 \pm 0.020$ \\
\hline Increase in reactivity index & $0.117 \pm 0.051$ & $0.125 \pm 0.076$ & $0.116 \pm 0.042$ & $0.017 \pm 0.072$ \\
\hline \multicolumn{5}{|c|}{$\begin{array}{l}\text { An increase in the reactivity index higher than } 0.3 \text { (IR more } \\
\text { than } 30 \% \text { ) was also observed in most patients after all types of }\end{array}$} \\
\hline \multirow[t]{2}{*}{ Parameter } & $\begin{array}{l}\text { VA transposition } \\
\text { in } C C A n=67\end{array}$ & Anastomosis & $\begin{array}{l}\text { Excision of } \\
\text { tortuosity }\end{array}$ & $\begin{array}{l}\text { Reconstructive } \\
\text { surgery }\end{array}$ \\
\hline & $\mathbf{M} \pm \mathbf{S D}$ & $\mathbf{M} \pm \mathbf{S D}$ & $\mathbf{M} \pm \mathbf{S D}$ & $\mathbf{M} \pm \mathbf{S D}$ \\
\hline Age at the time of surgery & $60.45 \pm 8.66$ & $69.97 \pm 7.33$ & $76.46 \pm 8.05$ & $70.09 \pm 6.94$ \\
\hline $\begin{array}{l}\text { Time from the onset of the disease to } \\
\text { surgery }\end{array}$ & $4.73 \pm 3.28$ & $4.53 \pm 2.73$ & $4.50 \pm 1.80$ & $3.69 \pm 1.99$ \\
\hline Blood flow before $\mathrm{VA}, \mathrm{ml} / \mathrm{min}$ & $65.08 \pm 18.34$ & $58.12 \pm 19.10$ & $75.11 \pm 21.52$ & $57.48 \pm 15.83$ \\
\hline Blood flow after $\mathrm{VA}, \mathrm{ml} / \mathrm{min}$ & $120.83 \pm 20.62$ & $111.52 \pm 18.38$ & $118.71 \pm 24.63$ & $113.95 \pm 17.21$ \\
\hline Increase in blood flow through VA, & $55.18 \pm 23.42$ & $52.14 \pm 16.38$ & $46.29 \pm 18.19$ & $56.48 \pm 17.30$ \\
\hline
\end{tabular}




\begin{tabular}{lcccc}
\hline $\mathrm{ml} / \mathrm{min}$ & & & & \\
$\begin{array}{l}\text { Total blood flow in both VAs before } \\
\text { surgery, } \mathrm{ml} / \mathrm{min}\end{array}$ & $214.27 \pm 22.59$ & $209.35 \pm 25.63$ & $212.96 \pm 26.24$ & $211.49 \pm 24.24$ \\
$\begin{array}{l}\text { Total blood flow in both VAs after } \\
\text { surgery, } \mathrm{ml} / \mathrm{min}\end{array}$ & $271.33 \pm 26.23$ & $252.74 \pm 52.29$ & $271.14 \pm 30.37$ & $268.91 \pm 20.25$ \\
$\begin{array}{l}\text { Increase in Total blood flow in both } \\
\text { VAs }\end{array}$ & $59.26 \pm 23.20$ & $57.00 \pm 21.46$ & $58.18 \pm 27.29$ & $57.42 \pm 23.43$ \\
\hline
\end{tabular}

The analysis of the volumetric blood flow rates showed a decrease in the clinical manifestations of VBI in patients with an increase in the total volumetric blood flow rate in VA of more than $250 \mathrm{ml} / \mathrm{min}$ among the patients who were operated on $(\mathrm{p}<0.05)$. This phenomenon was observed in the majority of patients with various forms of VBI. An increase in total volumetric blood flow of more than $250 \mathrm{ml} / \mathrm{min}$ was observed in most patients after various types of interventions on the segment I of the VA.

Favorable results, including a decrease or disappearance of VBI clinical symptoms, were observed in most patients with an increase in the total volumetric blood flow by $250 \mathrm{ml} / \mathrm{min}$ or more, and unfavorable results, deterioration or recurrence of VBI clinical symptoms, were observed in patients with a total volumetric blood flow after VA less than $250 \mathrm{ml} / \mathrm{min}$. and in all patients of the control group. Our proposed technique provides stable long-term effects starting from the first day of surgical treatment. In two cases, it was used at the third stage of cervical osteochondrosis with disc protrusion up to $5 \mathrm{~mm}$ with manifestations of instability and with moderate discovascular conflict. We achieved remission of clinical manifestations of vertebrobasilar insufficiency and improved blood flow by $10-15 \%$. The follow-up lasted for 9 months.

\section{V.CONCLUSION}

Using the developed algorithm for the selection of patients for surgery and interventions performed in 50 patients with clinical symptoms of VBI who experienced no positive effects of pharmacotherapy for 6 months, we achieved clinical improvements after surgery in $80 \%$ of the patients. Clinical improvements persisted 1 year later in $75 \%$ of patients and 3 years later in $68 \%$ of patients.

The analysis of long-term outcomes showed good longterm clinical results following reconstructive interventions in patients with VBI clinical symptoms. Long-term pharmacotherapy outcomes do not reach $40 \%$. The advantages of the proposed treatment method include the prophylactic focus, simplicity of manipulations, and good perspectives in both neurosurgical and neurological hospitals, as well as availability and affordability.

\section{ACKNOWLEDGMENT}

None.

\section{References}

[1] X-L. Lin, Z-Y. Zheng, Q-S. Zhang, Z. Zhang, and Y-Z. An, "Expression of miR-195 and its target gene Bcl-2 in human intervertebral disc degeneration and their effects on nucleus pulposus cell apoptosis," J. of Orthop. Surg. And Researvh., 2021, vol. 16, no. 1, art. no. 412.

[2] J. He, C. Ding, H. Liu, T. Wu, K. Huang, B. Wang, Y. Hong, and Y. Liu, "Is there a relationship between bony fusion after anterior cervical discectomy and fusion and heterotopic ossification after cervical disc arthroplasty in hybrid surgery?" Spine, 2020, vol. 45, no. 24, pp. E1653E1660.

[3] R. G. Power, and B. A. van Adel, "Delayed middle cerebral artery occlusion following endovascular coiling of carotid terminus aneurysm," Interdiscip. Neurosurg.: Adv. Techniq. Case Manag., 2021, vol. 26, art. no. 101308.

[4] S. Niu, X. Zhai, Y. Chen, H. Yang, C. Yang and M. Li. "Optimal indicators for identification of compensatory sagittal balance in patients with degenerative disc disease," BMC Musculoskel. Disord., 2021, vol. 2, no. 1, art. no. 211.

[5] Q. Hong, W. LI, J. Ma, P. Jiang, and Y. Zhang, "Endovascular treatment of vertebral and basilar artery aneurysms with low-profile visualized intraluminal support device," BMC Neurolog., 2021, vol. 21, no. 1, art. no. 198.

[6] J. de Rooij, B. Harhangi, H. Aukes, G. Groeneweg, D. Stronks, and F. Huygen, "The effect of percutaneous nucleoplasty vs anterior discectomy in patients with cervical radicular pain due to a single-level contained soft-disc herniation: A randomized controlled trial," Pain Physic., 2020, vol. 23, no. 6, pp. 553-564.

[7] K. Khalid, and A. Saifuddin, "Pictorial review: imaging of the spinal manifestations of achondroplasia," The Brit. J. Radiol., 2021, vol. 94, no. 1123, art. no. 20210223.

[8] M. Sagar, C. Stenor, and S. Rosenbaum, "Severe cerebral haemodynamic impairment treated with bypass surgery," Ugeskrift for Laeger, 2021, vol. 183, no. 3, art. no. V09200659.

[9] R., Bram, A. P. See, and S. Amin-Hanjani, "Intervention for symptomatic vertebrobasilar disease," J. Neurosurg. Sci., 2021, vol. 65, no. 3, pp. 327-347.

[10]P. L. Grundy, B. M. Hons, T. J. Germon, and S. G. Steven, "Transpedicular approaches to cervical uncovertebral osteophytes causing radiculopathy," Neurosurg., 2000, vol. 93, no. 1, pp. 21-27.

[11]E. A. Oudeman, J. P. Greving, R. M. Van Den Berg-Vos, G. J. Biessels, E. E. Bron, R. Van Oostenbrugge, J. De Bresser, and L. Jaap Kappelle, "Nonfocal transient neurological attacks are associated with cerebral small vessel disease," Stroke., 2019, vol. 50, no. 12, pp. 35403544 . 
[12] T. Mishra, G. Raj, and S. Dwivedi, "High riding innominate artery: An unusual pulsatile pretracheal mass," Radiol. Case Reports., 2021, vol. 16, no. 7, pp. 1732-1735.

[13] Y. Nariai, T. Takigawa, R. Suzuki, A. Hyodo, and K. Suzuki, "Stent-assisted coil embolization for an unruptured vertebral artery-posterior inferior cerebellar artery aneurysm with retrograde access via type 1 persistent primitive proatlantal artery: A case report," Intervent. Neuroradiol., 2021, vol. 27, no. 3, pp. 397-401.

[14] M. Massara, A. Alberti, and P. Volpe, "Early and midterm results of endovascular treatment of thoracic aorta diseases: a single-center experience," Seminars Vasc. Surg., 2020, vol. 32, no. 3-4, pp. 111-116.

[15] G. M. Barbagallo, and F. Certo, "The unfeasible made feasible: Lumbar minimally invasive hybrid stabilization with dynamic rod and mini-open transforaminal lumbar interbody fusion," J. of Neurosurg. Sci., 2020, vol. 64, no. 6, pp. 571-577.

[16] K. D. Kim, G. A. Hoffman, H. W. Bae, A. Redmond, and J. Jackson, "Ten-year outcomes of one- and two-level cervical disc arthroplasty," The Spine J., 2019, vol. 19, no. 9, p. 57.

[17] A. Khalil, and S. A. M. Nashef, "An alternative surgical approach to subclavian and innominate stenosis: a case series," J. Cardiothor. Surg., 2010, vol. 5, p. 73.

[18]I. Sh. Karabaev, D. V. Svistov, A. V. Kandyba, V. V. Savello, and G. I. Kharitonov, "Surgical treatment of occlusive-stenotic lesions of the cerebral arteries" In: Collection of Lectures on Topical Issues of Neurosurgery, St. Petersburg: ELBI-SPb, 2008, pp. 192-278.

[19]E. A. Kim, "Clinical picture, diagnosis and surgical treatment of pathological deformities of the main arteries of the head," Moscow: Research Institute of Ambulance named after N.V. Sklifosovsky, 2016.

[20] V. V. Kryuchkov, E. M. Rakhadilov, V. S. Karavaev, and Sh. Medetbekov, "Features of the treatment of cervicooccipital trauma," Bull. Kazakh Nat. Med. Univer., 2015, vol. 1, pp. 276-278.

[21] S. R. Chintalaphani, S. S. Pineda, I. W. Deveson, and K. R. Kumar, "An update on the neurological short tandem repeat expansion disorders and the emergence of longread sequencing diagnostics," Acta Neuropath. Com., 2021, vol. 9, no. 1, art. no. 98.

[22] M. V. Mudryakova, "Long-term results of treatment of patients with atherosclerotic occlusion of the internal carotid artery," Nizhny Novgorod: South Ural State Medical University, 2018.

[23] Yu. V. Novikov, I. N. Starovertov, S. A. Grachev, M. A. Shchepin, and E. A. Volkov, "Experience of surgical prevention of ischemic stroke in the vertebrobasilar system," Angiol. Vascul. Surg., 2016, vol. 22, no. 2, pp. 263-265.

\section{Author Contributions:}

Beslan S. Dzhilkashiev: Conceptualization, Investigation, Formal analysis and Writing - original draft.
Gennadiy I. Antonov: Investigation, Formal analysis and Writing - original draft and Writing - review \& editing. Gennadiy E. Chmutin: Investigation, Formal analysis and Writing - original draft and Writing - review \& editing.

Keith Simfukwe: Investigation, Formal analysis and Writing - original draft and Writing - review \& editing. Edward R. Miklashevich: Investigation, Formal analysis and Writing - original draft and Writing - review \& editing.

\section{Creative Commons Attribution License 4.0 (Attribution 4.0 International , CC BY 4.0)}

This article is published under the terms of the Creative Commons Attribution License 4.0

https://creativecommons.org/licenses/by/4.0/deed.en US 